\title{
UN TRÍPTICO IDENTIFICADO DE ADRIAEN THOMASZ KEY ATRIBUIDO A ANTONIO MORO EN ESPAÑA
}

El estudio de las dos puertas de un tríptico de gran tamaño con los retratos de los donantes y santos patronos en grisalla, atribuidas hasta ahora a Antonio Moro, nos inclina por razones de técnica y estilo a restituirlas hoy a Adriaen van Key contribuyendo a la ampliación de la monografía más reciente de K. Jonckheere.

Palabras clave: Retrato; Siglo XVI; Flandes; San Jerónimo; Santa Clara.

Study of the two doors of a large triptych with portraits of the donors and patron saints in grisaille, attributed until now to Antonio Moro, have led to the conclusion that for stylistic and technical reasons they were painted by Adriaen van Key, thereby contributing to the amplification of the most recent monograph by J. Jonckheere.

Key words: Portrait; 16th Century; Flanders; Saint Jerome; Saint Clare.

Las dos puertas de un tríptico de gran tamaño con los retratos de sus donantes, hombre y mujer, acompañados de sus santos patronos, objeto de estudio en estas páginas, eran conocidas en referencia escrita desde principios del siglo XX (figs. 1 a 4), testificando su origen en el coleccionismo aristocrático de Cádiz, y publicadas en el boletín del Museo Provincial de Bellas Artes de la ciudad con juicios críticos alusivos a su valor y propuesta la autoría a Antonio Moro ${ }^{1}$. El origen alcanza los últimos años del siglo XIX. Pero es muy posible que estuviera en la ciudad andaluza en fechas del encargo y adquisición del tríptico. Aquí llegan las puertas de cerramiento de una tabla central de 2 metros de alto por 0,80 de ancho. Duplicando las medidas los laterales que posiblemente acogerían una escena de la vida de Cristo como en los trípticos del Louvre y Amberes que, más adelante, tendremos ocasión de tratar.

Hemos citado la referencia escrita en 1927 con los dos retratos atribuidos a Antonio Moro, opinión justificable para aquellos años, pero la misma propuesta continuó en catálogo de la galería Ansorena en 1984, con un estudio crítico en la revista de arte Antiquaria $^{2}$, y repetido en artículos sucesivos con ocasión de su exposición ${ }^{3}$. En fecha reciente, Joanna Woodall, en la última monografía consagrada a Antonio Moro, acepta esta misma autoría ${ }^{4}$. Hasta aquí el estado de la cuestión. Nosotros proponemos a Adriaen Thomasz Key.

${ }^{1}$ Quintero, Pelayo, "Dos retratos inéditos pintados por Antonio Moro", Boletín del Museo de Bellas Artes, Cádiz, 1927, p. 93.

2 "La opinión del experto", Revista Antiquaria, Madrid, 1984, n. ${ }^{\circ} 9$.

${ }^{3}$ Ballesté, J., "Ansorena presentó dos tablas de Moro en treinta millones", ABC, 28-12-1984, p. 106; Cambio 16, 1985, n. ${ }^{\circ} 684$, p. 77.

${ }^{4}$ Woodall, J., Anthonis Mor, Art and Authority, 2007, p. 73. 


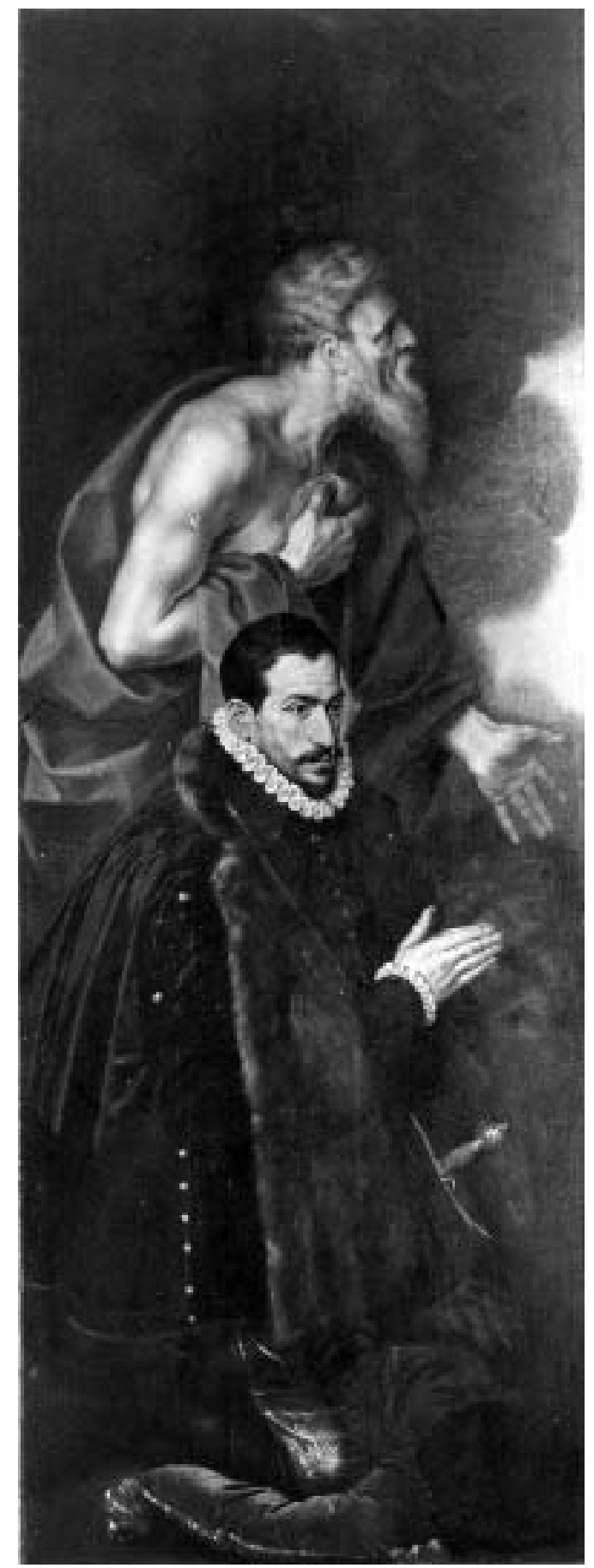

Fig. 1. Adriaen Thomas Key. Puerta lateral del Tríptico con retrato de San Jerónimo y donante, colección privada Madrid.

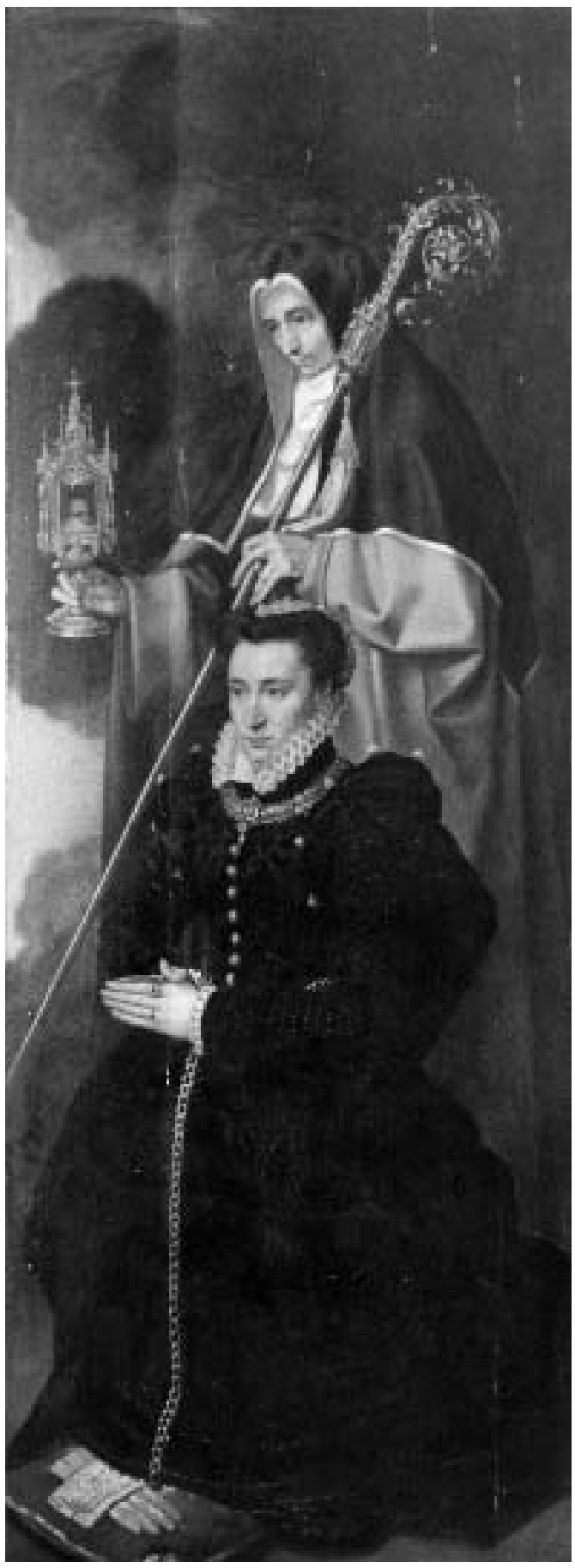

Fig. 2. Adriaen Thomas Key. Puerta lateral del Tríptico con retrato de Santa Clara y una señora, colección privada Madrid. 
El origen más antiguo de las dos tablas está en la familia Rojo y Sojo en Cádiz, pasando a sus herederos. Una tabla queda en Cádiz y otra pasa a Barcelona sin precisar su heredero. El retrato con la mujer arrodillada y Santa Clara es propiedad ahora de Dña. María Alvear y Saint Yust, y quedó en depósito con otras pinturas de su propiedad en el museo para su estudio por un tiempo. No conocemos la historia externa de las tablas ni a la familia, que posiblemente podrían hilar estudiosos de Cádiz de donde proviene ${ }^{5}$.

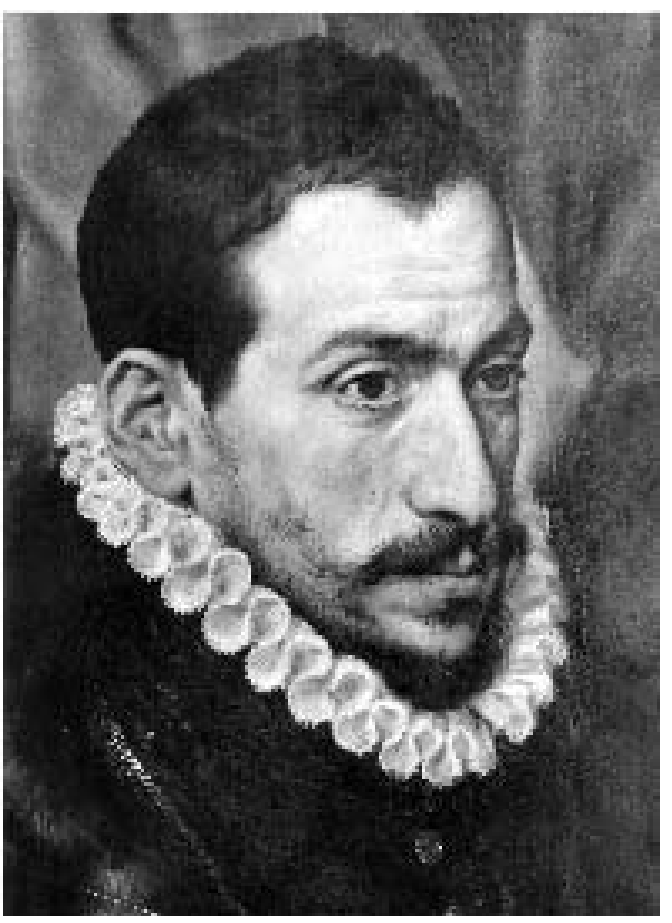

Detalle Fig. 1.

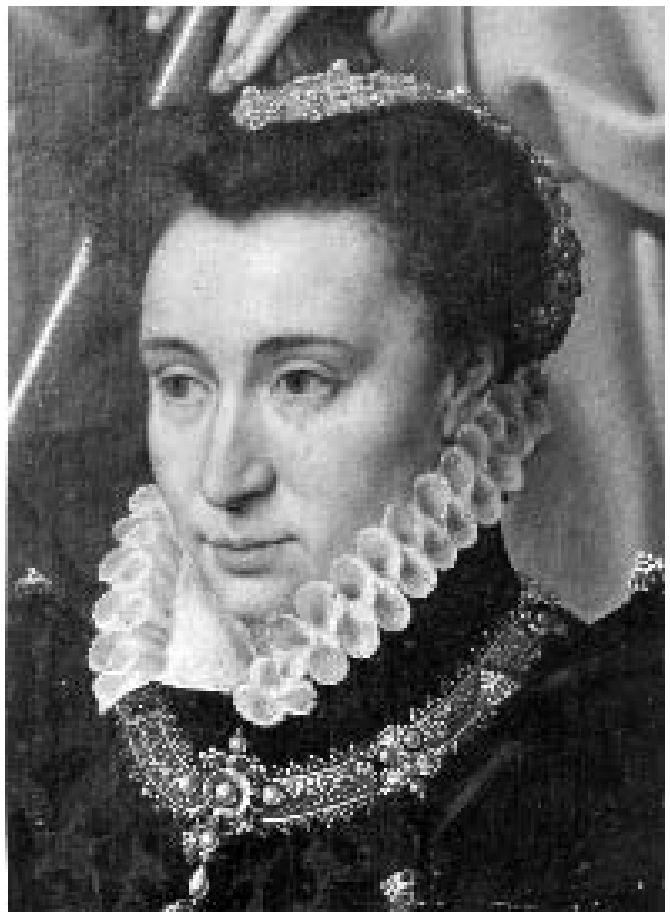

Detalle Fig. 2.

Todos los indicios inclinan a pensar en una importación directa de Flandes a mediados del siglo XVI. Por estas fechas llegan pinturas y enseres a tierras de Andalucía de aquellos estados del Imperio. La presencia de artistas flamencos y de pinturas en la ciudad es conocida sobradamente para entrar en consideraciones genéricas. Tanto en el norte como en el sur de la península fue impresionante la importación de tablas y lienzos de piedad del Renacimiento y Barroco. Es razonable pensar que este tríptico fuera un encargo más de una pudiente familia española, residente en Flandes y de regreso a su país natal.

Nos viene a la memoria recordar situaciones paralelas con encargos del tríptico de la Virgen de las Nieves por D. Antón Cerezo a Joos van Cleve desde el lejano señorío de Agaete en Gran Canaria ${ }^{6}$. No

${ }^{5}$ MAYer, Arte Español, n. ${ }^{\circ}$ 12, 1934-1935, p. 209. En este artículo el profesor Mayer publicó un número notable de tablas góticas españolas y óleos del XVI que formaban parte de sus colecciones pero ninguna alusión a las puertas del tríptico flamenco.

${ }^{6}$ Hernández Perera, "Joos Van Cleeve y el Tríptico flamenco de Agaete", Anuario de Estudios Canarios, XI-XVIII, 1965-1968, p. 35; DíAZ PAdrón, M., en Splendeurs d'Espagne Europalio 85, Bruxelles, et le villes belges (1500-1700), 1985, T. II, p. 503. 


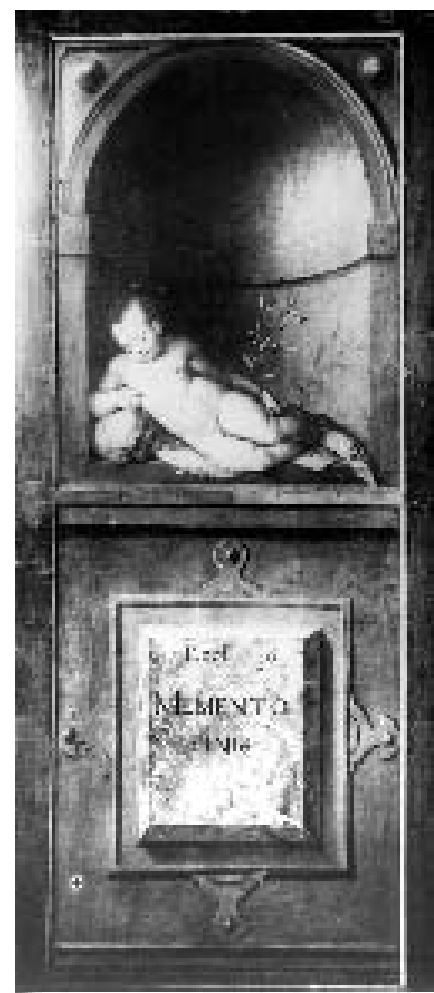

Fig. 3. Adriaen Thomas Key. Reverso. "Memento Finis", colección privada Madrid.
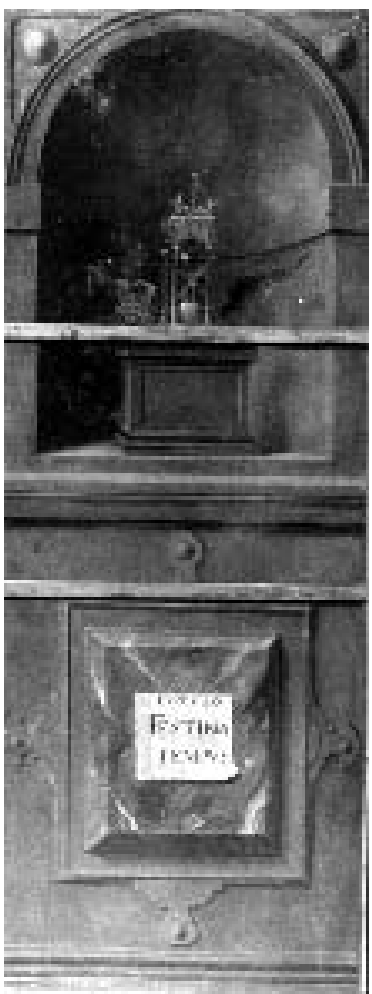

Fig. 4. Adriaen Thomas Key. Reverso. "Festina Tempus", colección privada Madrid.

es necesario insistir en la dificultad de este encargo en punto tan lejano. Los esposos están retratados junto a sus hijos. Don Antón Cerezo solicitó desde las islas con ostentoso orgullo un tríptico "al mejor pintor que hubiere, dedicado a nuestra Señora de la Concepción, y ordeno que a su llegada se coloque sobre el altar mayor de la iglesia, a la memoria de mi alma”. Así fue. Todo un alarde de poderío 7 . Igual propuesta debió hacer D. Juan López Gallo con su mujer e hijos en el tríptico de Groeningemuseum de Brujas a cargo de Pierre Pourbus ${ }^{8}$, pintor del emperador como Joos Van Cleve, que también fue de Francisco I de Francia y Enrique VIII de Inglaterra.

Pero más próximo al que estudiamos por autor y circunstancias es el tríptico del Museo del Louvre con los retratos de Antonio del Río y Doña Eleonora López de Villanueva (figs. 5 y 6). Por fortuna la historia externa nos es conocida en este caso. Sabemos que fue encargado para la Iglesia de Artselaer y transportado a Burgos, temiendo las revueltas iconoclastas que asolaron los Países Bajos del Norte bajo dominio español ${ }^{9}$. No sólo nos importa por tratarse del mismo autor sino por estar en el camino de España y responder bien al estudio comparativo.

7 Díaz Padrón, M., Canarias, la Atenas del Atlántico, 2003, p. 21.

${ }^{8}$ Huvenne, P., Pierre Pourbus, Peintre Brugeois, 1524-1584, 1984, p. 181, n. ${ }^{\circ} 10$.

9 Estella, M., "Noticias documentales sobre ¿Moro o Key? y sobre Caravaggio”, Archivo Español de Arte, n. ${ }^{\circ} 69$, 1996, 273-276, p. 345. JonckheEre, K., Adriaen Thomasz. Key (c. 1545-c. 1589), Portrait of a calvinist painter, 2007, p. 121, n. $^{\circ} 101 \mathrm{a}$ y $101 \mathrm{~b}$. 


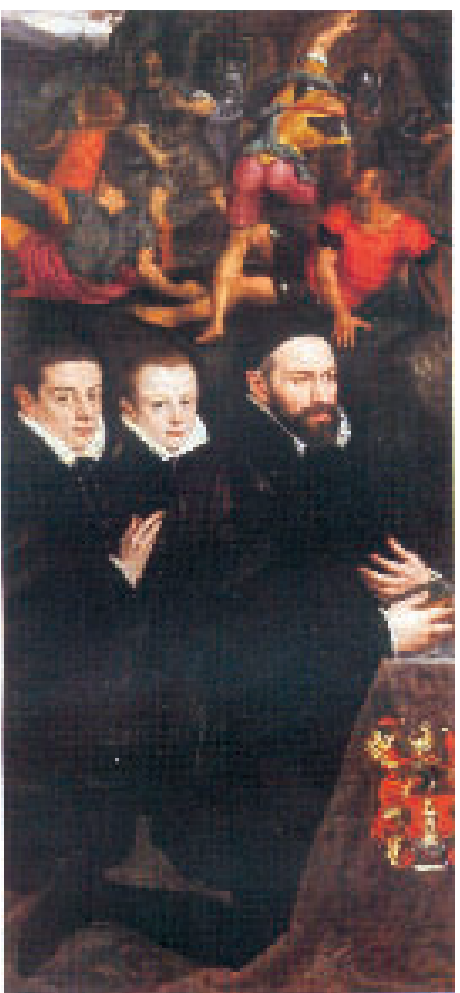

Fig. 5. Adriaen Thomas Key. Tríptico con retrato de Antonio del Río. Museo del Louvre.

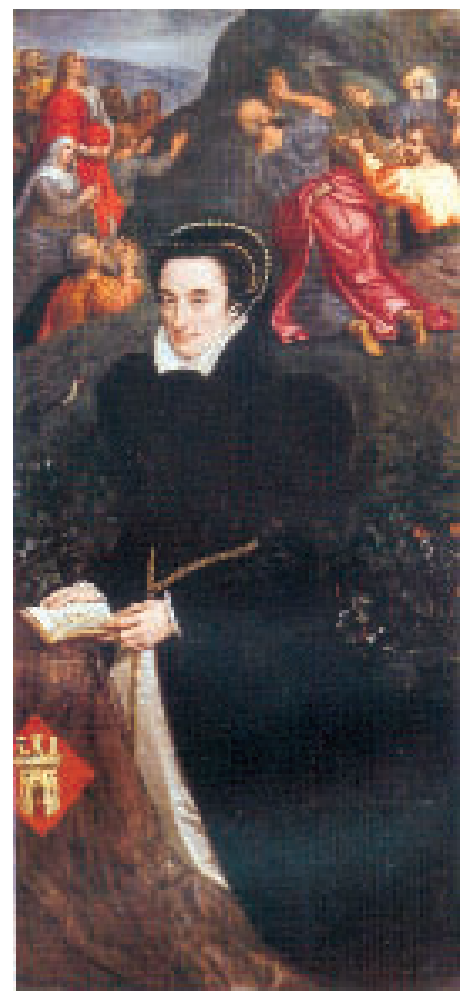

Fig. 6. Adriaen Thomas Key.

Tríptico con retrato Eleonora López Villanueva. Museo del Louvre.

También reúne a una familia española éste de Cádiz hoy en Madrid. Esto podría parecer muy posible, por proceder de suelo español y conscientes de los nobles residentes en el Norte. Esto podría ser igual aquí con probada afición a los pintores flamencos y gusto por los retratos que fijan sus imágenes con fidelidad, por encima de la lisonja como escribe Pacheco ${ }^{10}$. También los rasgos del caballero de piel oscura está más en consonancia con prototipos meridionales. Tanto Adriaen Thomas Key como Antonio Moro están en contacto con las vías de España, aunque Moro esté más con la del Imperio.

Los dos santos patronos comparten igual territorio bajo un cielo de nubes grises en tonos típicos de Adriaen Thomasz Key. San Jerónimo golpea su pecho con una piedra, mientras extiende la otra suplicando a Dios por su protegido. El rostro vuelto de tres cuartos hacia el fondo ayuda al protagonismo del caballero arrodillado a sus pies. El esquema se repite para Santa Clara con los hábitos y habituales símbolos. De hecho sigue la fórmula marcada por la tradición en los siglos XV y XVI (fig. 7).

10 SÁnchez CAntón, J., Fuentes literarias del Arte Español, T. II, p. 189; el retrato era una necesidad perentoria para el español y testigo de perdurar en el tiempo. Escribe Carducho: "no hay persona que piense que no retratarse es pérdida de grandeza en su república" (DíAZ PAdróN, M., La pintura flamenca del siglo XVII en España, 1976, T. I, folio 101). 
Es impactante el potencial táctil que transmiten los preciosos objetos de orfebrería que portan. El realismo lo logra el pintor igual en las telas y pieles como en la dureza de la piedra y metal contrastando con la blanda permeabilidad de la carne. La técnica es garante de la formidable conservación, sin alteración, salvo los viejos barnices y escasa acumulación de excrecencias. La monumentalidad de los personajes y la arquitectura coincide con lo más típico de Adriaen Thomasz Key, pero aquí el espacio está libre. La materia pétrea la desplaza al reverso en contraposición a los retratos Gillis de Smidt y Maria de Deckere y sus hijos del Museo Real de Amberes ${ }^{11}$ con igual concepción pero con poderosa arquitectura clásica detrás de los personajes.

También el tríptico de Madrid difiere del otro del Louvre por la acumulación sobre los retratos de una Resurrección y una Asunción en competencia con los retratos de Antonio del Río y de Eleonora de Villanueva. Hoy se sabe que una antigua restauración ocultó aquellas escenas con una capa oscura que duró hasta hoy $^{12}$.

A la altura de estas reflexiones es comprensible la confusión de los retratos de Key y de Moro si olvidamos hábitos de diseño y textura. A. Th. Key es más lineal y detallista al tratar los rostros y manos. No alcanza la impactante mirada de Antonio Moro, ni intenta retratos de cuerpo entero que toma de Tiziano para satisfacer la etiqueta de los Austrias.

Los trípticos de los museos de Amberes y Louvre valen para reconocer la misma silueta y el mismo tratamiento de los adornos y trajes en las esposas con tres cuartos de perfil. San Jerónimo recuerda el diseño de Judas en la Santa Cena del reverso de las tablas de Amberes: los brazos y mano de San José en la Sagrada Familia del Museo de Filadelfia y el torso

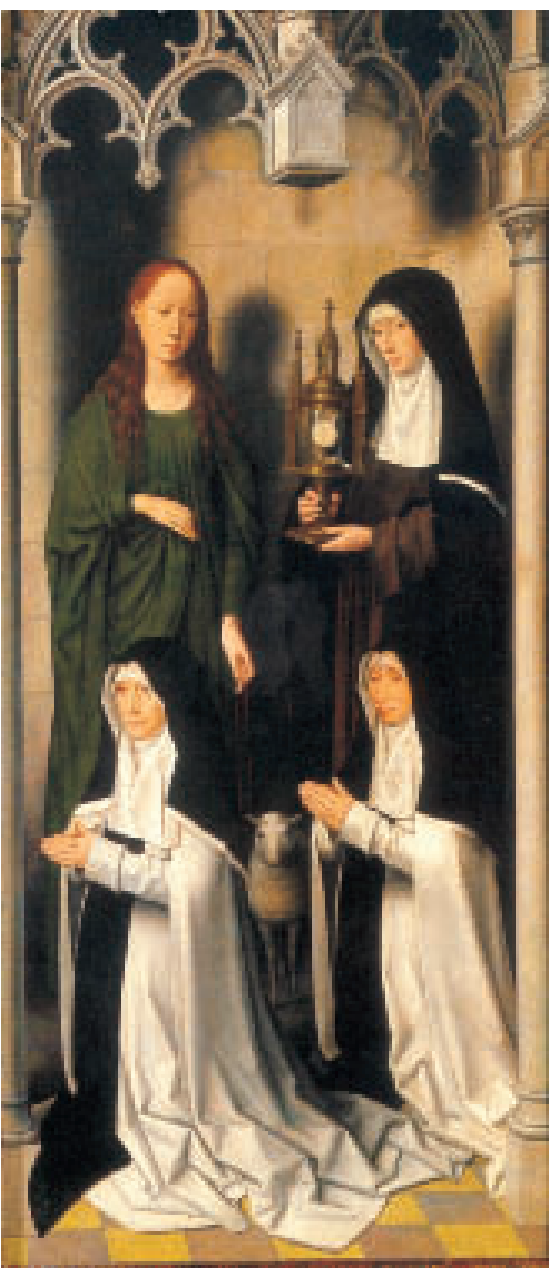

Fig. 7. Hans Memling. Tríptico de la Virgen con Santos. Hospital de San Juan de Brujas. Puerta de tríptico con Santa Clara. y plegados de San Jerónimo de la Galería de Dublín. Esto coincide con el estilo de los retratos objeto de nuestro estudio (fig. 8). Antonio Moro está

11 JONCKHEERE, K., op. cit., p. 119, n. ${ }^{\circ}$ A99, Idem 2006, p. 479.

12 Catalogue Raisonné des peintures du Moyen-Age, de la Renaissance et des Temps Modernes. Peintures Flamandes $d u$ XV et $d u$ XVI siècle. Musée du Louvre, París, 1953, p. XL. y Coremans, B., De portretten van Pillen Key (loor 1516-1568), unpublished MA thesis, K.U., Lovain, 2000. Es interesante señalar la existencia de esta pintura en España, importada por dicho noble para el Convento de la Trinidad de Burgos. En documento redactado en 1594 dice haberlo retirado de la Iglesia de Artselaer por temor a la destrucción de la iglesia. Elogia su calidad y envía a Burgos para que sus herederos la pongan en la capilla de la Resurrección. Debemos estas noticias a Margarita Estella, op. cit., pp. 273276 (1996) 345-349. El tríptico fue visto por Don Antonio Ponz y sabemos que lo requisó el General Darmagnac. El interrogante que se hace Margarita Estella al no encontrar las escenas referidas a la Resurrección y Asunción, narradas en los documentos tiene respuestas ahora. No hay duda al levantar la capa oscura que las cubría por cambios de gusto para destacar las imágenes retratadas. 


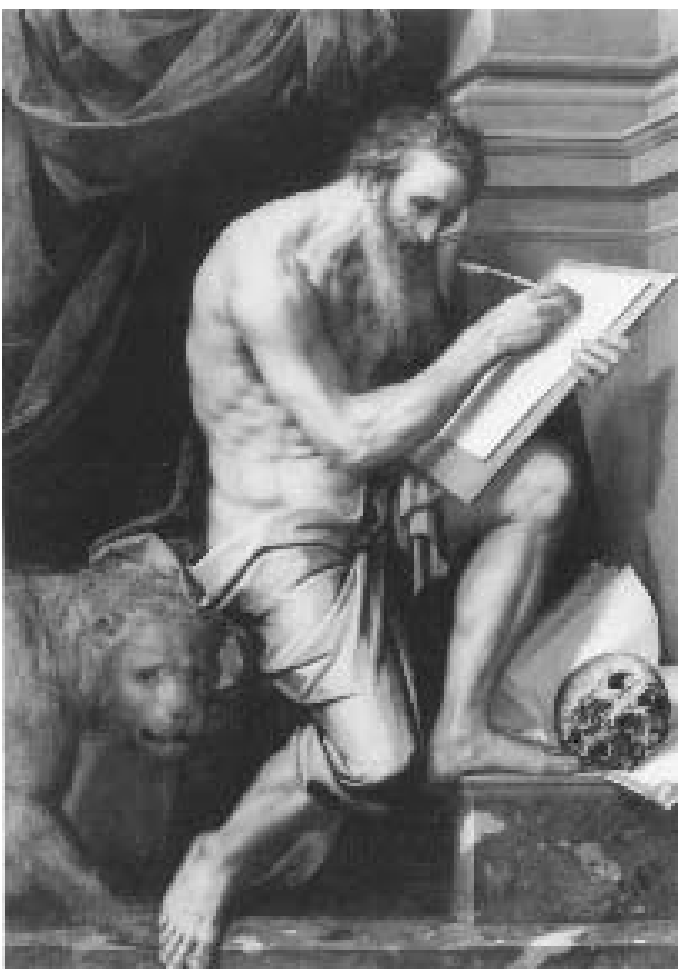

Fig. 8. Adriaen Thomas Key. San Jerónimo en su estudio. Galería Nacional de Irlanda. Dublín.

lejos de lograr la poderosa anatomía y solidez de los santos citados.

Key igual que Moro dominan la visión centrípeta del retrato de origen español. Esto es más hondo en el retrato de Antonio Moro. Key marca los perfiles de la nariz con sombra más oscura cuando Antonio Moro los difumina en suave ósmosis con el espacio.

Más interesante es el análisis comparativo con los retratos de medio cuerpo del hombre del Museo de Bruselas y la mujer con igual cuello, hombreras ${ }^{13}$ y busto de Gillis Beys y joven en colección privada de Bélgica ${ }^{14}$. Son distintos modelos pero es igual diseño, precisión técnica y sombra. Tampoco está lejos de esta técnica el retrato de grupo del Museo del Prado ${ }^{15}$.

Agregando formulismos típicos de A. Th. Key como la comisura de los labios en las jóvenes y una cadena que cae a lo largo del vestido, igual en los retratos de medio cuerpo de la mujer joven citada en Madrid, Hermitage $y$ trípticos de Amberes y Louvre. El peinado lo utiliza igual en los de Ana de Nassau, también en el Hermitage, y joven del Museo de Reinnes. Parece modalidad de las mujeres jóvenes, pues más frecuente es el uso de la toca en las mayores.

A. Th. Key se complace en los pormenores de las manos y orejas, mientras que Moro los funde en una síntesis óptica más próxima a conquistas del siglo XVII.

Hombre y mujer están pensativos y absortos en el más allá. Sentimiento igual al retrato del padre de familia del Museo del Prado. Mira al espectador recordándole lo vano de la vida al señalar el cráneo y el reloj de arena. Esto repite A. Th. Key en el reverso de los retratos que estudiamos. Todo sentido como un trampantojo afín a las modas del siglo XVI. Esto carece de interés en la producción de Antonio Moro. La placa de mármol fingida se divide en dos zonas: la puerta del donante y San Jerónimo reúne a un niño apoyado en un cráneo. Su pareja lleva el reloj de arena con alas extendidas y una nave sostenida por cuatro columnitas: símbolos de la vida que pasa. Dos inscripciones en capitales repiten el Anuncio de Eclesiastés 36: 10.: Festina tempus et memento finis ut enarrant mirabilia tua (acuérdate que el tiempo transcurre ligero). Conviene apuntar la caligrafía de letras y los números, idénticos en inscripciones de otras tablas del mismo pintor en reverso de los retratos con alusiones a las postrimerías ${ }^{16}$.

No es obvia nuestra hipótesis hispanista llamar la atención al sentimiento histórico y testimonial de los dos santos: San Jerónimo y Santa Clara: ambos en el punto de mira de la piedad de los españoles en estos lustros.

\footnotetext{
13 Díaz Padrón, M., Archivo Español de Arte, 1980, p. 381; Ibidem, 2007, p. 79, n. ${ }^{\circ}$ A12.

14 Ibidem, 2007, p. 91, Fig. A38.

15 Díaz PAdrón, M., en El legado Villaescusa adquisiciones: un mecenas póstumo, 1992-1993, pp. 48-59.

${ }^{16}$ Puede comprobarse en las reproducciones de la monografía citada (Vid. pp. 244 y 266).
} 
La orden de San Jerónimo es de origen español. La "casa" del santo estaba en el Monasterio de Nuestra Señora de Guadalupe en Extremadura. Son innumerables los sitios y lugares consagrados a su advocación por Carlos V y Felipe II: Yuste y El Escorial ${ }^{17}$. Santa Clara iluminó las tierras de Castilla ${ }^{18}$, y arraigó con pasión en los Países Bajos hasta revivir en la archiduquesa Isabel Clara Eugenia ${ }^{19}$.

Nos parece oportuno un sumario viaje de Key en España, prueba que estas tablas que hoy le restituimos no es excepcional. Pienso que exista más obra perdida por localizar. El marqués de Leganés, Don Diego de Mexía, poseyó un San Jerónimo en su testamentaría, localizada hasta el siglo XIX en España ${ }^{20}$. La fama de A. Th. Key la ratificó Pacheco a fines del siglo XVI y XVII ${ }^{21}$. El museo del Prado adquirió en fecha reciente el retrato de grupo citado; y réplica de Guillermo el Taciturno (William the Silent)22 está en la colección Thyssen-Bornemisza (inv. 208); y una señora en colección privada de Madrid, son antigua atribución a Moro. Originales posee el Palacio de Liria: un retrato del Duque de Alba, D. Fernando Álvarez de Toledo. Está desde 1568 en la familia ducal con referencia en los libros de Van Mander en $1604^{23}$. En cuanto al Retrato de Señora de la antigua colección Real se tiene por discutida (n. $\left.{ }^{0} 1280\right)^{24}$.

MATÍAs DíAz PADRÓN Museo Nacional del Prado

${ }^{17}$ RÉAU, L., Iconographie de l'art Chrétien, vol. III, 2, p. 741.

18 Ibidem, vol. III, 1, p. 317. Vorágine, Santiago de la, La leyenda dorada, Cap. 236, pp. 975-977. Real Fundación de la capilla y monasterio de Religiosas Franciscas Descalzas de la primera Regla de Santa Clara, que en la Villa de Madrid dotó y fundó la Serenísima Señora Doña Juana de Austria, Infanta de Castilla y Princesa de Portugal. Madrid, 1769.

19 J. B. KNIPPING, op. cit., Tomos 1 y 2, pp. 153, 303, 464; RogGen, Heribert, "Influence de Claire d'Assise aus Pays Bas. Collectanea franciscana", 1992, 62 (1-2). La Santa reproduce el rostro de Isabel Clara Eugenia en el boceto y tapices en La Eucaristía. Held, Julius S., The oil sketches of Peter Paul Rubens. A Critical Catalogue, vol. II, New Jersey, 1980.

20 Desgraciadamente exportado en fechas posteriores (JonCKHEERE, K., op. cit., p. 128, A112).

21 Pacheco, Arte de la Pintura, edición Sánchez Cantón, 1956, Tomo II, p. 153; Díaz Padrón, M., La Pintura Flamenca del siglo XVII en España, Tomo 1, folios 48 y 103.

22 JONCKHEERE, K., op. cit., p. 99, A55.

23 Van Mander, K., Het Schilder-boeck, Harlem, 1604.

24 Jonckheere. Reconocida la atribución por mí propuesta a A. Th. Key en la biografía al pintor de Jonckheere. 